\title{
Male duct ectasia associated with HIV infection
}

\author{
A M R Downs, M Fisher, D Tomlinson, A Tanner
}

The incidence of male duct ectasia (periductal mastitis) is extremely rare, only eight cases having been reported. The underlying cause (as in females) is uncertain. Two cases in HIV positive males of recurrent unilateral nipple lesions are reported with histology consistent with duct ectasia. At presentation neither patient had an AIDS defining illness. An impaired immunity secondary to HIV infection may result in an increased susceptibility to repeated nipple infections, and the clinical as well as histological features of duct ectasia. The consideration of HIV infection in future cases of male duct ectasia may be warranted.

(Genitourin Med 1996;72:65-66)

Keywords: HIV; duct ectasia; mastitis

\section{Introduction}

Duct ectasia consists of $1-2 \%$ of all symptomatic breast conditions in women. ${ }^{1}$ The syndrome consists of non-cyclical mastalgia, nipple discharge, nipple retraction, peri-alveolar abscess, mammilliary fistulae and a subareolar lump, with or without overlying skin inflammation. Young female patients tend to present with breast pain and/or a breast lump. Histology shows severe periductal inflammation around non-dilated ducts. Older patients possess dilated ducts, disrupted elastic lamina and variable fibrosis, with little active inflammation, reflecting the end-stage of a recurrent inflammatory assault. ${ }^{2}$ The initial cause of the inflammation is unknown.

Only eight cases of male duct ectasia have been reported previously. We report a further two cases presenting from a single centre that may suggest an increased incidence in HIV infected homosexual males.

Urinary Medicine, Marys Hospital, Praed Street, London $\mathbf{W} 1$ 1NY, UK

A M R Downs

$M$ Fisher

D Tomlinson

A Tanner

Address correspondence to:

Dr A M R Downs

Accepted for publication

6 March 1995

\section{Case reports}

Case 1: A 30 year old homosexual male, diagnosed HIV positive in April 1993, presented one month later complaining of a four week history of a lump behind the right nipple with an intermittent blood-stained discharge. His family practitioner had aspirated a similar lump in 1989. Other than a ventolin inhaler, he took no regular medication. On examination, small cystic lesions around the areolar were noted as well as a left nipple ring. The right nipple had never been pierced. Full blood count, electrolytes, liver function and chest radiograph were within normal limits. $\mathrm{He}$ was hepatitis $\mathrm{B}$ immune from a previous infection and syphilis serology was negative. CD4 count was 180 cells $/ \mathrm{mm}^{3}$. A fine needle aspiration was insufficient for diagnosis and was sterile on culture, so an excision biopsy of the major ducts beneath the right nipple was undertaken in September 1993. No other treatment was given.

Histology (fig 1) showed fibrous connective tissue containing dilated and distorted ducts. There was periductal fibrosis and a chronic inflammatory cell infiltrate in which plasma cells were seen. Some ducts were partially obliterated by granulomatous tissue.

There were no post-operative complica-

Case 2: A 44 year old homosexual male was diagnosed HIV positive in November 1984.

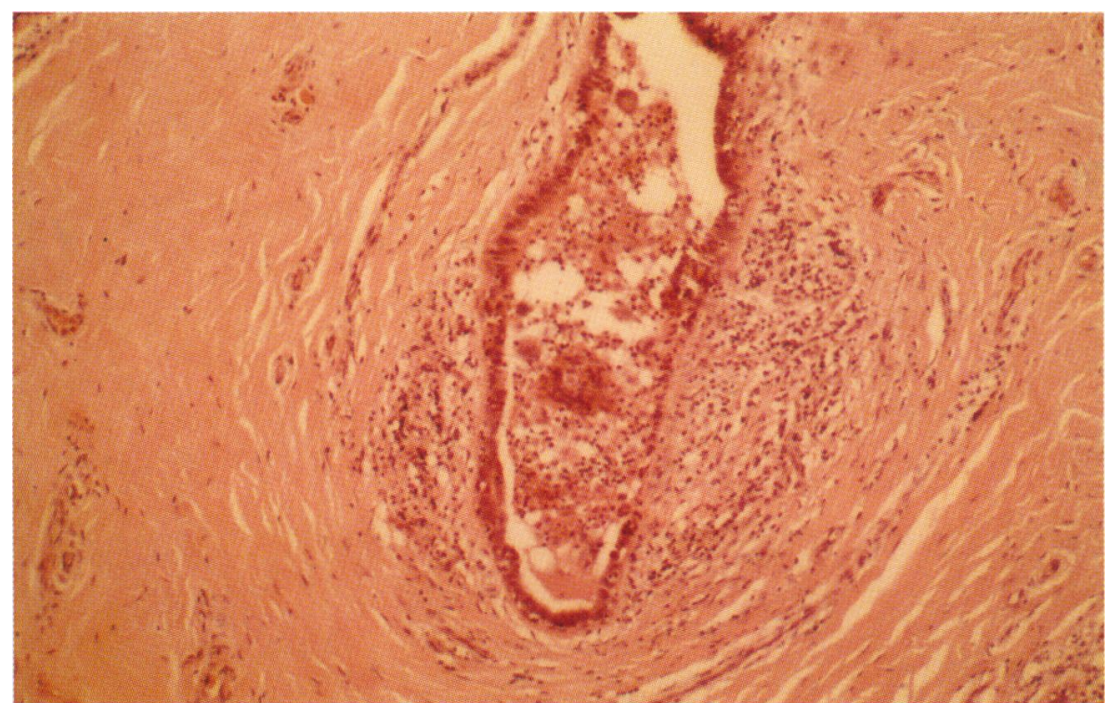

Figure 1 Distorted infiltrated major breast duct of case 1. $\mathrm{He}$ first presented with a blood-stained discharge from his right nipple in March 1989. In 1987 he had noted a lump under his right nipple that had resolved spontaneously after two months. His nipples had never been pierced. Past medical history included hepatitis $B$ in 1977 and shingles in 1985 and $1989 . \mathrm{He}$ had started AZT in March 1988 but discontinued three months later, and was on no other medication. Full blood count, electrolytes and liver function were normal. CD4 count was 350 cells $/ \mathrm{mm}^{3}$. The lesion was treated with oral amoxycillin and flucloxicillin and resolved. In August 1993 he presented with an eighteen month history of recurrent purulent discharge from the same nipple, which settled once more with oral amoxycillin and flucloxicillin, only to reoccur. A nipple swab taken grew anaerobic streptococcus. An excision biopsy of the major ducts beneath the right nipple was undertaken one month later without antibiotic cover. 


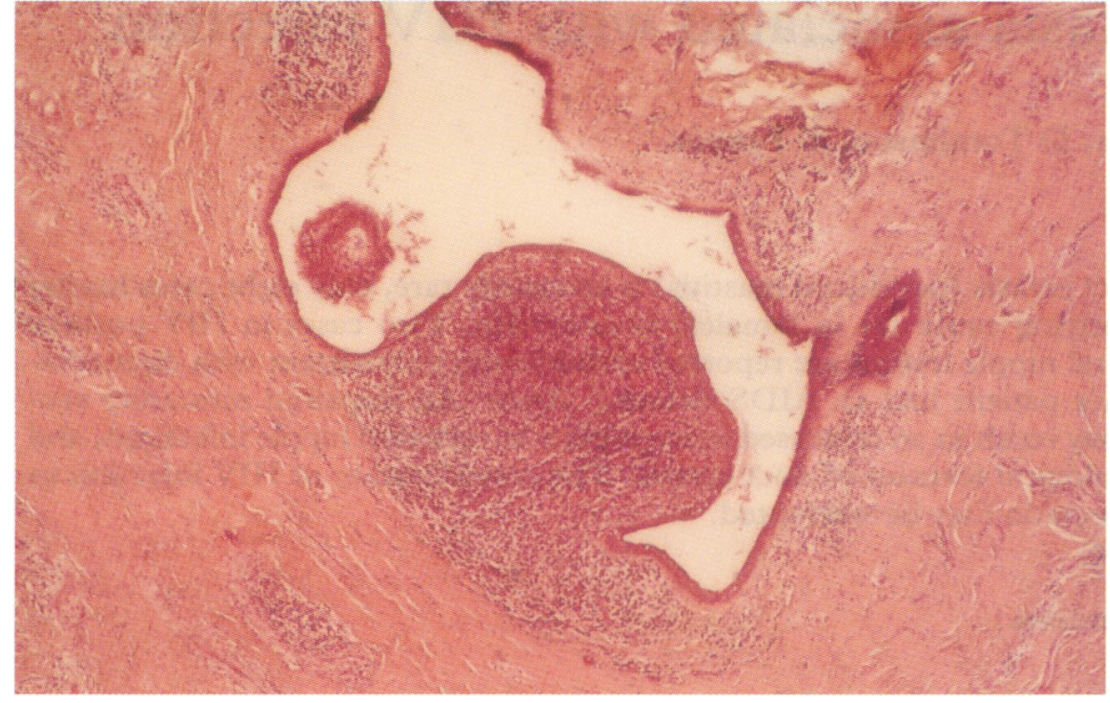

Figure 2 Classic breast duct ectasia in case 2.

Histology (fig 2) showed dilated ducts with scattered foci of granulomatous inflammation.

A wound infection followed which responded to flucloxicillin and no recurrences have appeared at four months.

\section{Discussion}

Male duct ectasia was first described in 1974 by Tedeschi and McCarthy. ${ }^{3}$ Three further cases were reported in 1979 by Mansell and Morgan, ${ }^{4}$ and an additional four cases in the early $1980 \mathrm{~s}$, one associated with a prolactin adenoma. ${ }^{5-7}$ One post mortem study of predominantly elderly, asymptomatic males has shown a $25 \%$ incidence, and suggests that the condition is quite common but undiagnosed. ${ }^{8}$ However, it is more likely that as the ducts age, there is natural dilation secondary to tissue changes in the elderly. ${ }^{1}$

In women with duct ectasia, aerobic and anaerobic organisms are present in a high proportion $(62 \%)$ of nipple discharges and in all abscesses examined in some studies. ${ }^{9}$ Infectious organisms have been isolated in previous male cases and in one of our own. Following excision biopsy, there is a $50 \%$ recurrence in females, ${ }^{10}$ and an increased postoperative infection rate in the absence of antibiotic cover. ${ }^{11}$ Formal duct excision yields the best results.

Neither of our patients had AIDS defining illnesses, but their CD4 cell counts were sig nificantly reduced. There would therefore be के generalised predisposition to infection? Trauma may play a part in nipple infections and in this respect, the use of nipple clamps and associated "sex toys" may be relevanto Both of the patients described had never beets regular users of torture instruments, and th $\mathbb{B}$ sexual exploits of the previous eight male case were not commented upon. Repeated infec $-\overrightarrow{-}$ tions may damage duct architecture, thus establishing the features of duct ectasia. Witho two cases of such a rare condition, associate with HIV, clinicians may wish to consider the possibility of undiagnosed, asymptomatic HIV infection in any subsequent male duct ectasiक् cases that present.

1 Dixon JM. Periductal mastitis/duct ectasia. World f Sur T 1989;13:715-20.

2 Dixon JM, Anderson TJ, Lumsden AB, Elton RA, Rober MM, Forrest APM. Mammary duct ectasia. Br $\mathcal{f}$ Surg 1983;70:601-3.

3 Tedeschi LG, McCarthy PE. Involutional mammary duạ ectasia and periductal mastitis in a male. Humag Pathology 1974;5(2):232-6.

4 Mansell RE, Morgan WP. Duct ectasia in the male. $\mathrm{Br}$ \% Surg 1979;66:660-2

5 Detraux P, Benmussa M, Tristant H, Garel L. Breast dis ease in the male: galactographic evaluation. Radiolog 1985;154:605-6.

6 Ashford MT, Corcoran GD, Haqqani MT. Periduct要 mastitis and mammary duct ectasia in a male. Postgrae

Med F 1985;61:621-3.
7 Chan KW, Lau WY. Duct ectasia in the male breast. $A u \stackrel{\overrightarrow{5}}{ }$ NZ f Surg 1984;54:173-6. 8 Anderson JA, Gram JB. Male breast at autopsy. APMI\$

9 Brundred NJ, Dixon JM, Chetty U, Forrest APM: Mammillary fistula. $B r \mathcal{F}$ Surg 1987;74:466-8.

10 Browning J, Bigrigg A, Taylor I. Symptomatic and inciden tal mammary duct ectasia. $\mathcal{F} R$ Soc Med 1986;79:715-7.

11 Scholefield JH, Duncan JL, Rogers K. Review of a hospit experience of breast abscesses. Br $\mathcal{f}$ Surg 1987;74 469-70. 